\title{
INFLUENCE OF BASAL RELEASE OF NITRIC OXIDE ON SYSTOLIC AND DIASTOLIC FUNCTION OF BOTH VENTRICLES
}

Pankaj Mankad, FRCS(C/Th)

Magdi Yacoub, FRCS

\begin{abstract}
Nitric oxide is continuously released by coronary artery endothelium under basal conditions; it maintains vascular tone and regulates coronary blood flow. The objective of this study was to investigate the influence of this basal release of nitric oxide on right and left ventricular systolic and diastolic function. Isolated pig hearts perfused at a constant pressure with enriched autologous blood were used. Systolic and diastolic pressure-volume relationships of isovolumically contracting hearts were studied in the control setting and after addition of $1 \mathrm{mmol} / \mathrm{L}_{\mathrm{L}}-\mathrm{N}^{\mathrm{G}}$-monomethyl-arginine followed by $5 \mathrm{mmol} / \mathrm{L} \mathrm{L}$-arginine to the perfusate. Addition of $\mathrm{L}-\mathrm{N}^{\mathrm{C}}$-monomethylarginine caused an acute rise in coronary vascular resistance and a reduction in right and left ventricular systolic function as evaluated by the slope values of the pressure-volume curves, but had little effect on the diastolic function of either ventricle. L-Arginine restored the systolic function to the control level. This alteration in ventricular function was not a result of ischemia because myocardial oxygen consumption was not significantly affected by the acute increase in coronary vascular resistance induced by $\mathrm{L}-\mathrm{N}^{\mathrm{C}}$-monomethyl-arginine. We conclude that basal release of nitric oxide has no direct negative inotropic effect, but in fact plays an important role in preserving right and left ventricular systolic function and maintains the basal coronary vascular tone. (J Thorac Cardiovasc Surg 1997;113:770-6)
\end{abstract}

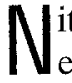
tric oxide (NO) is released continuously from endothelial cells under basal conditions by enzymatic conversion of endogenous L-arginine. ${ }^{1}$ It modulates vascular tone in large and small coronary arteries. Inhibition of NO synthesis causes reduction in myocardial blood flow in ex vivo experiments ${ }^{2}$ and produces coronary vasoconstriction in in vivo studies. ${ }^{3}$ However, the role of the basal release of NO in maintaining myocardial function in the normal heart has not been adequately investigated.

From the National Heart and Lung Institute, London, United Kingdom.

Supported by The National Heart and Lung Institute, London, United Kingdom.

Received for publication Feb. 12, 1996; revisions requested March 18, 1996; revisions received Nov. 6, 1996; accepted for publication Nov. 19, 1996

Address for reprints: Pankaj Mankad, FRCS (C/Th), Consultant Cardiac Surgeon, The Royal Hospital for Sick Children, Sciennes Rd., Edinburg EH9 1LF, Scotland, United Kingdom.

Copyright (C) 1997 by Mosby-Year Book, Inc.

$0022-5223 / 97 \$ 5.00+0 \quad \mathbf{1 2 / 1 / 7 9 3 3 7}$
We have previously shown that inhibition of basal NO release in the rat heart leads to depression of mechanical function. ${ }^{4}$ In these experiments, hearts were perfused with crystalloid solution. Perfusion of the isolated heart with blood for evaluation of myocardial function has obvious advantages. In addition, global myocardial function includes systolic and diastolic ventricular functions. There is evidence to suggest that one of the functions can be affected without apparent change in the other. In addition, for proper evaluation of myocardial function, it is imperative to study the function of both right and left ventricles simultaneously. With the use of $\mathrm{L}-\mathrm{N}^{\mathrm{G}}$-monomethyl-arginine (L-NMMA), a selective inhibitor of NO synthesis and L-arginine, we have investigated the influence of basal release of NO in maintaining right and left ventricular systolic and diastolic functions in the blood-perfused isolated pig heart.

\section{Methods}

Experimental design. Nine pigs of either sex, weighing between 45 to $62 \mathrm{~kg}$ each, were given atropine sulphate $(40 \mu \mathrm{g} / \mathrm{kg}$ ) plus ketamine hydrochloride $(10 \mathrm{mg} / \mathrm{kg}$ ) and 
anesthetized with intravenous propofol $(3 \mathrm{mg} / \mathrm{kg})$. They were intubated and supported on a volume-controlled ventilator. The anesthesia was maintained with $60 \%$ oxygen and $40 \%$ nitrous oxide ( 4 to $6 \mathrm{~L} / \mathrm{min}$ ). Pancuronium bromide $(0.08 \mathrm{mg} / \mathrm{kg})$ was given before performance of a median sternotomy. While the chest was being opened, 2 units of blood (each unit approximately $500 \mathrm{ml}$ ) was collected via a cannula inserted into a femoral artery to prime the perfusion circuit for functional evaluation. The pigs were heparinized with $300 \mathrm{IU} / \mathrm{kg}$ of beef-lung heparin. The pericardium was opened and the heart isolated, excised, and immediately immersed in cold $\left(4^{\circ} \mathrm{C}\right)$ Ringer's solution (Travenol Laboratories Ltd., Thetford, Norfolk, England). Prompt diastolic arrest was achieved by infusion of $300 \mathrm{ml}$ of St. Thomas' Hospital cardioplegic solution (David Bull Laboratories, Mulgrave, Victoria, Australia), cooled to $4^{\circ} \mathrm{C}$, into the aortic root. The hearts were weighed immediately after arrest and replaced in cold Ringer's solution.

While the heart was still immersed in cold Ringer's solution, intraventricular balloons connected to a pressure transducer were sutured to the annuli of the tricuspid and mitral valves. The left ventricle was vented by a small apical stab incision. A thermistor probe was inserted into the interventricular septum for continuous monitoring of myocardial temperature. The sinus node was crushed and two pacing wires were sutured to the right atrium. The aortic arch was clamped, a cannula was inserted into the innominate artery, and both the aorta and the cannula were deaired. The heart was then mounted on a retrograde perfusion apparatus consisting of a Watson-Marlow roller pump (Smith \& Nephew Watson-Marlow, Cornwall, England), a Capiox 300 hollow-fiber oxygenator with integrated heat exchanger (Terumo Corporation, Tokyo, Japan), and a $40 \mu \mathrm{m}$ blood filter (LPE 1440, Ultipor blood filter, Pall Biomedical Ltd., Portsmouth, England) via the cannula in the innominate artery and placed inside an insulated glass cylinder. The heart was immediately perfused in a nonpulsatile retrograde fashion with enriched autologous blood (hematocrit $24 \%$ to $28 \%$ ) containing D-ribose $1 \mathrm{gm} / \mathrm{L}$, insulin $20 \mathrm{IU} / \mathrm{L}$, and glucose 14.25 $\mathrm{mg} / \mathrm{min}$ at an aortic pressure of $50 \mathrm{~mm} \mathrm{Hg}$ and perfusate temperature of $28^{\circ} \mathrm{C}$. After 5 minutes of perfusion under these conditions, the aortic pressure was increased to 80 $\mathrm{mm} \mathrm{Hg}$ and the temperature brought up to $37^{\circ} \mathrm{C}$. The hearts were paced at a constant rate of 120 beats $/ \mathrm{min}$. Coronary flow was measured continuously by an on-line electromagnetic blood flow probe connected to a calibrated flow meter (Nihon-Kohden Corporation, Tokyo, Japan).

Experimental protocol. After 20 minutes of perfusion, samples of blood were collected from the arterial line and from the coronary sinus for the measurement of oxygen content. Functional evaluation of the isovolumically contracting hearts was aided by previously introduced intraventricular balloons and done by the method described by Weber, Janicki, and Shroff. ${ }^{5}$ Six hearts were used for these experiments. The zero volume for isovolumic ventricular contraction, defined as the volume at which the ventricle generates a diastolic pressure of 1 to $2 \mathrm{~mm} \mathrm{Hg}$, was determined for both ventricles by introduction of a measured quantity of normal saline solution into the intraven- tricular balloons. The balloons were then sequentially inflated with $10,20,30$, and $40 \mathrm{ml}$ of saline solution. At each balloon volume, transballoon left ventriculat systolic and diastolic and right ventricular systolic and diastolic pressures were recorded (control data).

L-NMMA was then added to the perfusate to give the final concentration of the antagonist at $1 \mathrm{mmol} / \mathrm{L}$. This dose was selected on the basis of a number of observations in control experiments. Three pig hearts were perfused with incremental doses of L-NMMA starting from $10^{-5}$ $\mathrm{mol} / \mathrm{L}$ and increasing by $10^{-1} \mathrm{~mol} / \mathrm{L}$ up to a maximum of $10^{-2} \mathrm{~mol} / \mathrm{L}$. This resulted in an acute increase in coronary vascular resistance (CVR) as determined by the quotient of perfusion pressure (in millimeters of mercury) and coronary flow (milliliters per minute) per gram heart weight. The dose of L-NMMA $(1 \mathrm{mmol} / \mathrm{L})$ that gave the maximum increase in CVR was selected for further experiments. The speed of the perfusion pump was adjusted to maintain perfusion pressure at $80 \mathrm{~mm} \mathrm{Hg}$. This resulted in reduction in coronary flow. The new value of coronary flow was recorded. After 15 minutes, arterial and coronary sinus blood samples were collected to measure oxygen content, and left and right ventricular functions were remeasured as described before (post-L-NMMA data). $\mathrm{L}$-Arginine was next added to the perfusate to achieve a final concentration of $5 \mathrm{mmol} / \mathrm{L}$. Perfusion pressure was maintained at $80 \mathrm{~mm} \mathrm{Hg}$. Coronary flow was recorded, and after 20 minutes of perfusion ventricular function was assessed as before (post-L-arginine data).

The stability of this preparation was determined by serial (every 15 minutes) evaluation of ventricular function in three experiments during continuous perfusion of hearts, without any additives to the perfusate, over 60 minutes. In three additional experiments, after the assessment of control ventricular function, L-arginine was added to the perfusate $(5 \mathrm{mmol} / \mathrm{L}), \mathrm{CVR}$ was recorded, and after 20 minutes repeat measurement of ventricular function was undertaken. The investigations were performed in accordance with the Guidance on the Operation of the Animals (Scientific Procedures) act of 1986, published by Her Majesty's Stationery Office, London.

Myocardial oxygen consumption. Myocardial oxygen consumption $\left(\mathrm{MVO}_{2}\right)$ was calculated from the oxygen content of arterial and coronary venous blood. The value was normalized with respect to the heart weight to give an $\mathrm{MVO}_{2}$ in milliliters of $\mathrm{O}_{2}$ per beat per $100 \mathrm{gm}$ of heart weight.

Myocardial function evaluation. From the values of transballoon systolic and diastolic pressures obtained at different balloon volumes, pressure-volume (P-V) curves were plotted for both the right and left ventricles. The slope of the systolic P-V curve, that is, peak elastance (in millimeters of mercury per milliliter), and the inverse slope of the diastolic curve, that is, ventricular compliance, were used as indices of systolic and diastolic ventricular functions, respectively. The slope values of diastolic P-V curves were obtained by plotting a regression line through the $P-V$ points.

Expression of results. The control and post-L-NMMA data on $\mathrm{MVO}_{2}$ were analyzed by a paired $t$ test. The control, post-L-NMMA, and post-L-arginine values of right and left ventricular elastance and compliance were 

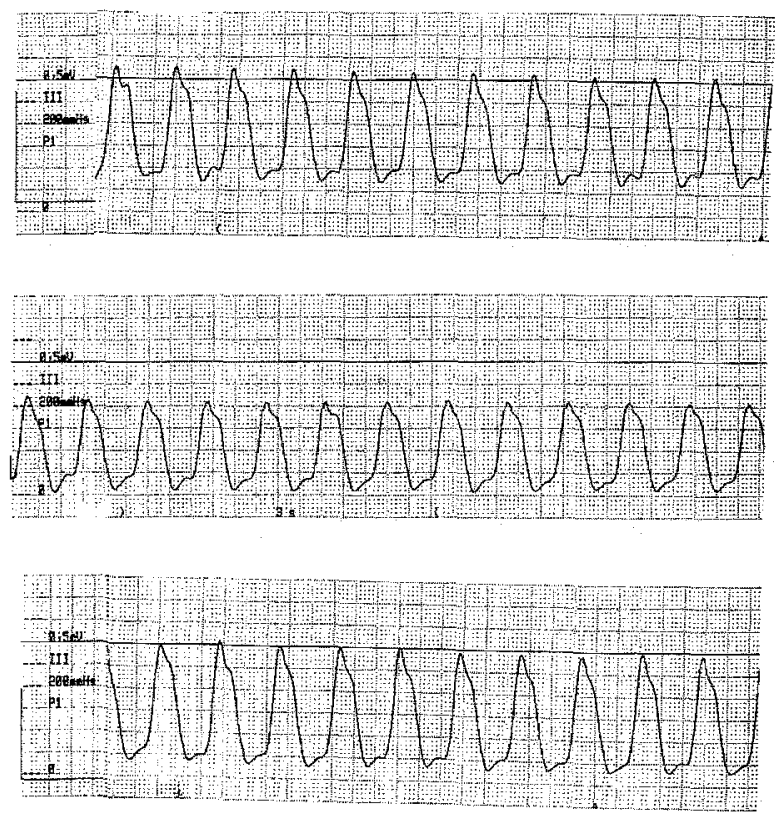

Fig. 1. An example, at the balloon volume of $40 \mathrm{ml}$, of the analog tracings used to generate a typical left ventricular P-V curve. The top tracing shows the control data, the middle tracing data after L-NMMA administration and the bottom tracing data after addition of L-arginine to the perfusate.

analyzed and compared for statistical significance by analysis of variance with Scheffe's correction. Significance was assumed when the $p$ value was less than 0.05 . All values are expressed as the mean plus or minus the standard deviation.

\section{Results}

There was no significant difference in the absolute values of systolic and diastolic pressures at different balloon volumes in the control experiments in which ventricular function was measured over 60 minutes of continuous perfusion without any additives. An example of the analogue tracings used to generate P-V curves is shown in Fig. 1.

Control, post-L-NMMA, and post-L-arginine coronary flow and CVR. Table I shows the coronary flow and the CVR in the control setting, after addition of $\mathrm{L}-\mathrm{NMMA}$, and after reversal of the effect of L-NMMA by L-arginine. Table I also depicts the representative values for right and left ventricular systolic and diastolic pressures at $20 \mathrm{ml}$ balloon volume. Control coronary flow was $2.025 \pm 0.14$ $\mathrm{ml} / \mathrm{min}$ per kilogram. CVR in the control conditions was $39.7 \pm 2.6 \mathrm{~mm} \mathrm{Hg} / \mathrm{ml}$ per minute per gram heart weight $(n=6)$. Soon after the addition of L-NMMA, this rose to $62.9 \pm 5.7 \mathrm{~mm} \mathrm{Hg} / \mathrm{ml}$ per minute per gram heart weight $(p<0.001)$, whereas after the addition of L-arginine there was a significant reduction compared with post-L-NMMA values to $44.5 \pm$ $2.8 \mathrm{~mm} \mathrm{Hg} / \mathrm{ml}$ per minute per gram heart weight $(p<0.001)$. Though the addition of L-arginine counteracted the increase in CVR induced by LNMMA, the values were still significantly higher as compared with the control observations $(p=$ 0.0115 ).

Control and post-L-NMMA $\mathrm{MVO}_{2}$. Table I shows the difference in oxygen content of arterial and coronary sinus blood plus the values of $\mathrm{MVO}_{2}$ before and after infusion of the preparation with L-NMMA. After L-NMMA was added to the preparation, the myocardium extracted an increased amount of oxygen from the arterial blood to compensate for the reduced flow. There was no significant difference in the $\mathrm{MVO}_{2}$ in the control setting, after the addition of L-NMMA, or after L-arginine infusion.

Control and post-L-NMMA ventricular function. Control and post-L-NMMA left and right ventricular systolic and diastolic function curves are plotted in Figs. 2 and 3. The addition of L-NMMA caused a shift to the right of the left and right ventricular systolic $\mathrm{P}-\mathrm{V}$ curves and resulted in reduction in the peak systolic elastance. The control left ventricular elastance of $4.55 \pm 0.63 \mathrm{~mm} \mathrm{Hg} / \mathrm{ml}$ was reduced to $3.08 \pm 0.24 \mathrm{~mm} \mathrm{Hg} / \mathrm{ml}(p<0.001)$; the control right ventricular elastance of $2.32 \pm 0.44 \mathrm{~mm} \mathrm{Hg} / \mathrm{ml}$ was reduced to $1.36 \pm 0.31 \mathrm{~mm} \mathrm{Hg} / \mathrm{ml}$ after $\mathrm{L}-\mathrm{NMMA}$ addition $(p=0.0014)$. The percentage reductions in elastance from the control values for the left and right ventricles were $31.2 \% \pm 9.7 \%$ and $41.0 \% \pm$ $12.04 \%$, respectively.

L-NMMA caused a shift to the right of the diastolic P-V curve and resulted in an increase in both left and right ventricular compliances as compared with the control values. The left ventricular compliance rose from $1.03 \pm 0.13 \mathrm{~mm} \mathrm{Hg} / \mathrm{ml}$ to $1.57 \pm 0.21 \mathrm{~mm} \mathrm{Hg} / \mathrm{ml}(p<0.001)$; the right ventricular compliance changed from $0.96 \pm 0.21$ $\mathrm{mm} \mathrm{Hg} / \mathrm{ml}$ to $1.08 \pm 0.18 \mathrm{~mm} \mathrm{Hg} / \mathrm{ml}(p=0.324)$.

Post-L-NMMA and post-L-arginine ventricular function. Figs. 2 and 3 show the left and right ventricular systolic and diastolic function curves after the addition of L-NMMA and L-arginine to the perfusate. The L-NMMA-induced decrease in systolic elastance of both ventricles was partially restored by L-arginine. Left ventricular elastance increased from $3.08 \pm 0.24 \mathrm{~mm} \mathrm{Hg} / \mathrm{ml}$ to $4.34 \pm 0.42$ 
Volume 113, Number 4

Table I. Findings in the control setting and after addition of $1 \mathrm{mmol} / L_{L}-N M M A$ followed by addition of 5 mmol/L L-arginine to blood-perfused, isolated, isovolumically contracting pig hearts $(n=6)$

\begin{tabular}{|c|c|c|c|c|c|c|c|c|}
\hline & $\begin{array}{c}\text { Coronary flow } \\
(\mathrm{ml} / \mathrm{min})\end{array}$ & $\begin{array}{c}\text { CVR } \\
(\mathrm{mm} \mathrm{Hg} / \mathrm{ml} / \\
\mathrm{gm} / \mathrm{min})\end{array}$ & $\begin{array}{c}\text { LV systolic } \\
\text { pressure } \\
(\mathrm{mm} \mathrm{Hg})\end{array}$ & $\begin{array}{c}L V \text { diastolic } \\
\text { pressure } \\
\text { (mm Hg) }\end{array}$ & $\begin{array}{c}R V \text { systolic } \\
\text { pressure } \\
(m m \mathrm{Hg})\end{array}$ & $\begin{array}{c}R V \text { diastolic } \\
\text { pressure } \\
(m m \mathrm{Hg})\end{array}$ & $\begin{array}{l}A_{C} V_{c} \\
\text { (vol \%) }\end{array}$ & $\begin{array}{c}\mathrm{MVO}_{2} \\
\text { (ml/beat/100 gm) }\end{array}$ \\
\hline$\overline{\text { Con }}$ & $427.5 \pm 49.7$ & $39.65 \pm 2.57$ & $125 \pm 9.7$ & $6.3 \pm 1.37$ & $59.8 \pm 4.9$ & $7.8 \pm 1.47$ & $1.75 \pm 0.22$ & $29.48 \pm 3.52$ \\
\hline Post-L-NMMA & $270.0 \pm 32.9^{*}$ & $62.9 \pm 5.66^{*}$ & $96.7 \pm 11.1$ & $5.5 \pm 1.5$ & $45 \pm 6.6$ & $8.2 \pm 1.2$ & $2.82 \pm 0.52^{*}$ & $29.7 \pm 3.71 \dagger$ \\
\hline Post-L-arginine & $380.0 \pm 31.8 \neq \S$ & $44.45 \pm 2.81+1$ & $114.3 \pm 11.1$ & $7.7 \pm 1.0$ & $59.7 \pm 7.1$ & $8.5 \pm 1.0$ & $2.11 \pm 0.46$ & $31.4 \pm 4.08$ \\
\hline
\end{tabular}

For details of the experimental protocol, refer to the text. Left and right ventricular pressures are those at a balloon volume of 20 inl. Values are mean plus or minus the standard deviations. $L V$, left ventricular; $R V$, right ventricular; $A_{c}-V_{c}$, myocardial oxygen extraction.

" $p<0.001$ compared with control value.

$\dagger p=0.8736$ compared with control value.

$\$ p<0.001$ compared with post-L-NMMA value.

$\S p=0.077$ compared with control value.

$\| p=0.0115$ compared with control value.

$\mathrm{mm} \mathrm{Hg} / \mathrm{ml}(p<0.001)$ and right ventricular elastance improved from $1.36 \pm 0.31 \mathrm{~mm} \mathrm{Hg} / \mathrm{ml}$ to $2.26 \pm 0.42 \mathrm{~mm} \mathrm{Hg} / \mathrm{ml}(p=0.0017)$. Though the post-L-arginine values of elastance were slightly higher as compared with the control observations, there was no significant difference between them. Compliances of both ventricles were also restored by L-arginine. Left ventricular compliance was $1.24 \pm 0.22 \mathrm{~mm} \mathrm{Hg} / \mathrm{ml}$ after L-arginine as opposed to $1.57 \pm 0.21 \mathrm{~mm} \mathrm{Hg} / \mathrm{ml}$ after L-NMMA ( $p=$ $0.025)$. Right ventricular compliance, after $\mathrm{L}$-arginine, was $0.94 \pm 0.16 \mathrm{~mm} \mathrm{Hg} / \mathrm{ml}$ in comparison with $1.08 \pm 0.18 \mathrm{~mm} \mathrm{Hg} / \mathrm{ml}$ after L-NMMA $(p=0.181)$. There was no significant difference between the post-L-arginine values of compliances and the control observations.

Addition of L-arginine to the perfusate immediately after control observations had no significant effect on CVR or ventricular systolic and diastolic functions.

\section{Discussion}

We have shown that in the isolated pig heart, coronary vascular tone is affected by continuous basal release of endothelium-derived NO, but blockade of this NO release does not lead to a state of myocardial ischemia. We have also shown that the basal release is critical for preserving systolic function of both the right and left ventricles. However, in this study little direct effect of basal NO on the diastolic function of ventricles was observed.

Under basal conditions NO is released by endothelium in response to mechanical factors such as shear stress and pulsatile flow. ${ }^{6,7}$ Several possible mechanisms may account for the observed effects of NO in our experiments. First, L-NMMA itself could have direct negative inotropic effects on the myocar- dium. This is, however, unlikely inasmuch as in myocyte experiments done with use of the method described by Harding and associates ${ }^{8}$ we have previously shown that in isolated rat myocytes L-NMMA ( $1 \mathrm{mmol} / \mathrm{L})$ has no significant effect on the amplitude of contraction or on velocities of contraction and relaxation. ${ }^{4}$ Second, addition of L-NMMA reduces coronary blood flow and produces a state of myocardial ischemia causing diminished contractility. This is an unlikely explanation because $\mathrm{MVO}_{2}$ in our experiments remained unaffected by blockade of NO release. This confirms previous observations in isolated rat and in vivo pig hearts that inhibition of NO synthesis reduces coronary flow but does not induce a state of ischemia. ${ }^{9}$ Third, NO inhibits norepinephrine release from sympathetic nerve endings. ${ }^{10}$ L-NMMA may enhance the release of norepinephrine and affect myocardial function. If so, its effect on myocardial contractility would be opposite of that encountered in our experiments. In these experiments hearts were isolated, that is, denervated, which thus makes this possible explanation invalid. Fourth, it is, therefore, most likely that the noted effect of basal NO release on myocardial systolic function was its direct action mediated by the cyclic guanosine monophosphate pathway. However, the observed increase in ventricular compliance after suppression of basal NO release by L-NMMA, suggesting preserved diastolic function, was a paradoxic finding. This is most likely to be an indirect effect. Diastolic properties of ventricles are affected by coronary blood volume. ${ }^{11}$ A modest increment in the end-diastolic P-V relationship is observed with an elevation in coronary perfusion pressure and flow. The reverse holds true if there is a decrease in coronary perfusion pressure and flow. A decrease in the total coronary blood 


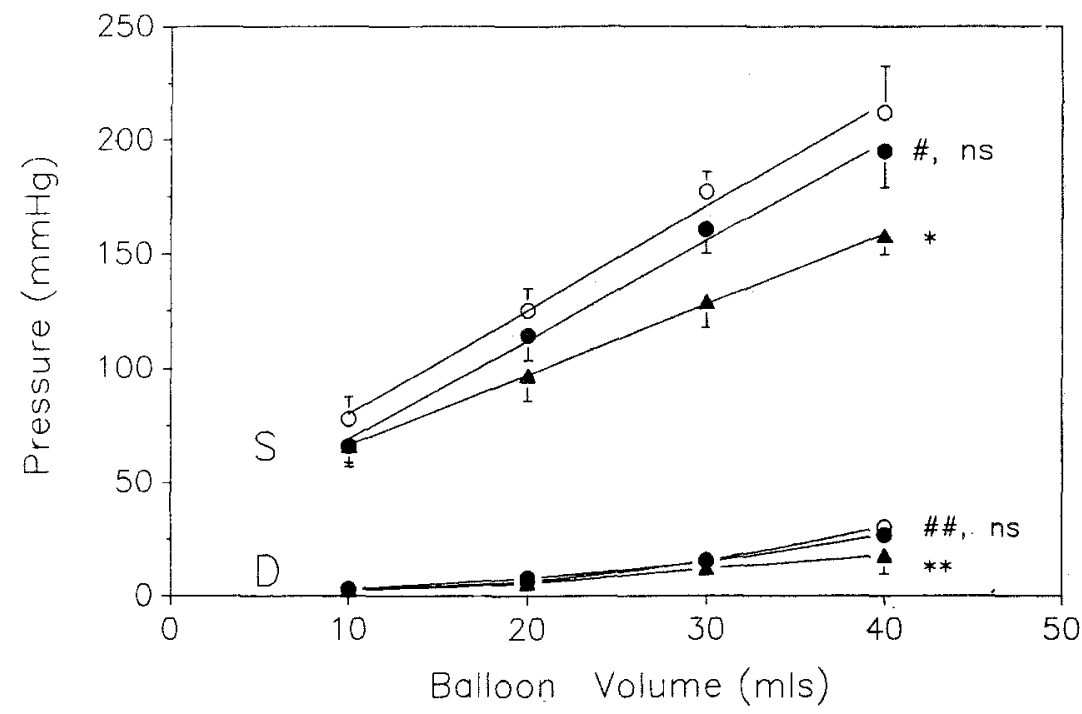

Fig. 2. Left ventricular systolic $(S)$ and diastolic $(D)$ P-V relationships of isovolumically contracting isolated pig hearts $(n=6)$ in the control setting (open circles), after infusion of $1 \mathrm{mmol} / \mathrm{L} \mathrm{L}-\mathrm{NMMA}$ to the blood perfusate (solid triangles), and after reversal of this effect by addition of $5 \mathrm{mmol} / \mathrm{L}$ L-arginine (solid circles). ${ }^{*} p<0.001,{ }^{* *} p<0.001$ compared with the control values; $\# p<0.001$, \#\# $=0.025$ compared with post-L-NMMA values; $n s$, not significant compared with the control values. The $p$ values refer to the ventricular elastance and compliance.

volume is, therefore, a most likely explanation for the apparent rightward shift in the diastolic P-V relation observed after suppression of NO release with L-NMMA.

In this study we used an isolated pig heart to assess ventricular function. There are several advantages in using this model. It is a denervated preparation; therefore myocardial function is not dependent on neurohumoral factors. Because the preparation is blood perfused and the hearts are subjected to cold cardioplegic arrest the in vivo situation encountered in cardiac operations and transplantation is simulated. The model allows critical assessment of both right and left ventricular systolic and diastolic functions. The limitations of this model include the nonpulsatile nature of perfusion and a closed recirculating preparation. Because pulsatility is a strong stimulus for basal NO release, it is conceivable that this preparation without pulsatility would have lower basal NO release than the in vivo situation. The failure of $\mathrm{L}$-arginine to completely reverse the effects of L-NMMA could be a result of the time lag between L-NMMA administration and $\mathrm{L}$-arginine infusion. Because the interaction between L-arginine and L-NMMA is competitive, the effects may be seen more clearly if L-arginine is infused from the beginning of the experiments. This difference could also be due to mechanical or pharmacokinetic changes in the microcirculation caused by the edema that may develop during the experiment.

The observed effect of physiologic NO release is in contrast to the action of pathologic quantities of NO on myocytes. ${ }^{12}$ It has been shown that stimulated release of $\mathrm{NO}$ has negative inotropic effects. ${ }^{12-14}$ Excessive production of NO, which occurs in conditions such as endotoxemia, reduces myocyte contractility ${ }^{13}$; this effect is identical to the action of cytokines on mammalian hearts, which is also mediated by NO. ${ }^{14}$ These paradoxic effects of NO on myocytes could be due to the different mechanisms that operate in its release. ${ }^{15}$ Basal release is physiologic and occurs by continuous stimulation of constitutive NO synthatase, whereas excessive release is triggered by activation of inducible NO synthatase in certain pathologic conditions.

The effects of physiologic NO release on myocardial function have been studied by other investigators. In isolated ejecting guinea pig hearts, GrocottMason and associates ${ }^{16}$ showed that exogenous NO typically enhances myocardial relaxation and reduces diastolic tone, without significantly altering the rate of force or pressure development; in human beings, the same group showed that endogenous NO 


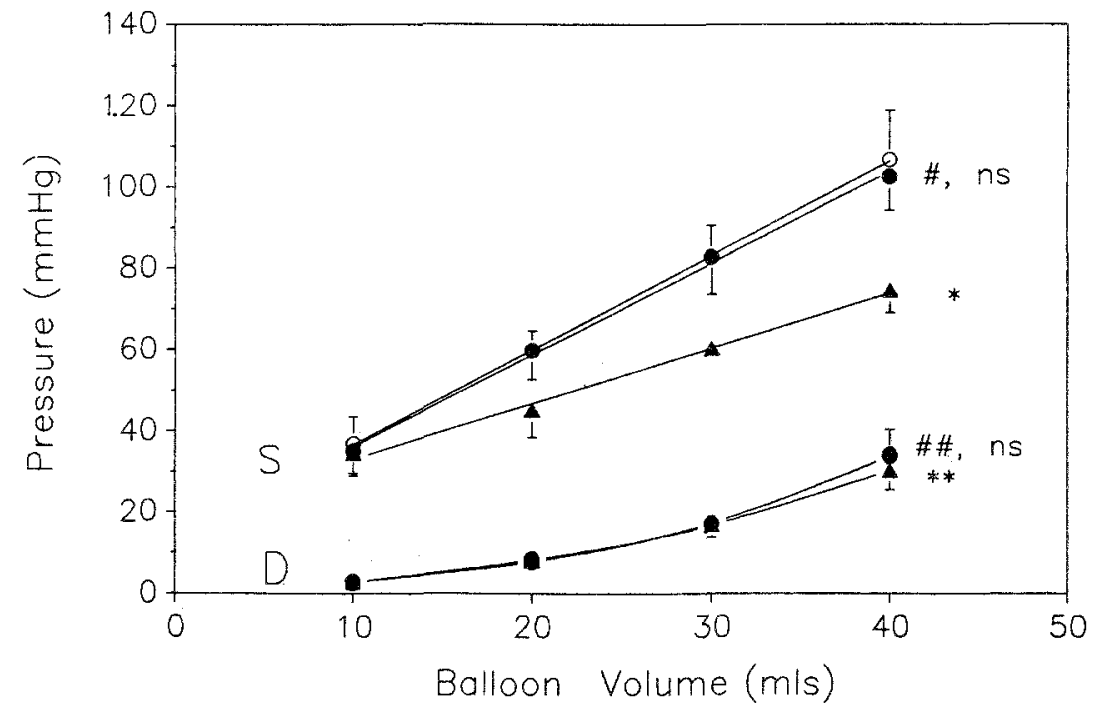

Fig. 3. Right ventricular systolic $(S)$ and diastolic $(D)$ P.V relationships of isovolumically contracting isolated pig hearts $(n=6)$ in the control setting (open circles), after infusion of $1 \mathrm{mmol} / \mathrm{L}$ L-NMMA to the blood perfusate (solid triangles), and after reversal of this effect by addition of $5 \mathrm{mmol} / \mathrm{L}$ L-arginine (solid circles). ${ }^{*} p=0.0014,{ }^{* *} p=0.324$ compared with the control values; $\# p=0.0017, \# \# p=0.181$ compared with post-L-NMMA values; $n s$, not significant compared with the control values. The $p$ values refer to the ventricular elastance and compliance.

modulates left ventricular relaxation in the intact heart. ${ }^{17}$ An influence of basal NO on left ventricular diastolic filling parameters has also been shown by Clarkson, Lim, and MacDonald ${ }^{18}$ in normal volunteers. In our experiments no direct effect on myocardial diastolic function was observed. This could be due to the limitation of the preparation or the lesser sensitivity of the measured parameter of diastolic function. Mohan, Sys, and Brutsaert ${ }^{19}$ showed a concentration-dependent positive inotropic effect of NO-releasing nitrovasodilators in isolated cat papillary muscle. With the same preparation they also showed that NO and prostaglandins released from endocardial endothelium interact with each other to regulate myocardial performance. ${ }^{20}$ In our study the effects of NO released from vascular endothelium or from endocardial endothelium ${ }^{21}$ could not be separated. However, the effects of vascular endothelium on myocardial contractile characteristics have been shown to be similar to those of endocardial endothelium in rat ventricular papillary muscles after Langendorff perfusion. ${ }^{22}$ It is likely that the observed effects of NO suppression in our experiments were due to inhibition of both vascular and endocardial NO.

The clinical implications of these findings are manifold. Endothelial function is often adversely affected by ischemia and reperfusion during routine cardiac operations and transplantation. ${ }^{23,24}$ It is conceivable that diminished basal release of NO in this setting contributes to reduction in myocardial systolic function and forms a part of reperfusion injury. In this context, it has recently been shown that in experimental preparations addition of the NO precursor L-arginine or of an NO donor during ischemia-reperfusion leads to improved recovery of myocardial contractile function. ${ }^{25-27}$ Coronary angioplasty, an established procedure for certain patients with coronary artery disease, also leads to endothelial damage and dysfunction. ${ }^{28}$ Significant depression in ventricular function has been described during angioplasty, which often persists after successful balloon dilation.In this study the shortterm influence of suppression of basal release of NO on myocardial function was reversible; however, it is possible that long periods of ischemia could result in a certain degree of irreversible myocardial damage in patients with coronary artery disease.

In summary, we have shown that basal release of NO, unlike stimulated pathologic release, has no direct negative inotropic effect but in fact plays an important role in preserving right and left ventricular systolic function and maintains the basal coronary vascular tone. Further clinical studies are 
needed to evaluate the role of NO in the recovery of myocardial function after ischemia and reperfusion. ${ }^{29}$ This could have a significant impact on the early results of cardiac operations and transplantation.

\section{REFERENCES}

1. Palmer RMJ, Rees DD, Ashton DS, Moncada S. L-Arginine is the physiological precursor for the formation of nitric oxide in endothelium-dependent relaxation. Biochem Biophys Res Commun 1988;153:1251-6.

2. Benyo Z, Kiss G, Szabo C, Csaki C, Kovach AGB. Importance of basal nitric oxide synthesis in regulation of myocardial blood flow, Cardiovase Res 1991;25:700-3.

3. Chu A, Chambers DE, Lin CC, Kuehl WD, Cobb FR. Nitric oxide modulates epicardial coronary basal vasomotor tone in awake dogs. Am J Physiol 1990;258:H1250-4.

4. Amrani M, O'Shea J, Allen NJ, et al. Role of basal release of nitric oxide on coronary flow and mechanical performance of the isolated rat heart. J Physiol 1992;456:681-7.

5. Weber KT, Janicki JS, Shroff SG. Measurement of ventricular function in the experimental laboratory. In: Fozzard HA, Jennings RB, Haber E, Katz AM, Morgan HE, eds. The heart and cardiovascular system: scientific foundations. New York: Raven, 1986:865-86.

6. Rubanyi GM, Romero JC, Vanhoutte PM. Flow-induced release of endothelium-derived relaxant factor. Am $J$ Physiol 1986;250:H1145-9.

7. Pohl U, Busse R, Kuon E, Bassenge E. Pulsatile perfusion stimulates the release of endothelial autocoids. J Appl Cardiol 1986;1:215-35.

8. Harding SE, Vescovo G, Kirby M, Jones SM, Gurden J, Poole-Wilson PA. Contractile responses of isolated rat and rabbit myocytes to isoproterenol and calcium. J Mol Cell Cardiol 1988;20:635-47.

9. Kirkeboen KA, Naess PA, Offstad J, Ilebekk A. Effects of regional inhibition of nitric oxide synthesis in intact porcine hearts. Am J Physiol 1994;266(4 pt 2):H1516-27.

10. Sakuma I, Togeshi $H$, Yasuda H, Gross S, Levi R. $\mathbf{N}^{G}$ methyl-4-arginine, an inhibitor of L-arginine-derived nitric oxide synthesis, stimulates renal sympathetic nerve activity in viva: a role for nitric oxide in the central regulation of sympathetic tone? Circ Res 1992;71:607-11.

11. Cross CE, Rieben PA, Salisbury PF. Influence of coronary perfusion and myocardial edema on pressure-volume diagram of left ventricle. Am J Physiol 1961;210:102-8.

12. Brady AJ, Warren JB, Poole-Wilson PA, Williams TJ, Harding SE. Nitric oxide attenuates cardiac myocyte contraction. Am J Physiol 1993;265(1 pt 2):H176-82.

13. Brady AJ, Poole-Wilson PA, Harding SE, Warren JB. Nitric oxide production within cardiac myocytes reduces their contractility in endotoxemia. Am J Physiol 1992;263:H1963-6.
14. Finkel MS, Oddis CV, Jacob TD, Watkins SC, Hattler BG, Simmons RL. Negative inotropic effects of cytokines on the heart mediated by nitric oxide. Science 1992;257:387-9.

15. Hare JM, Colucci WS. Role of nitric oxide in the regulation of myocardial function. Prog Cardiovasc Dis 1995;38: 155-66.

16. Grocott-Mason R, Anning P, Evans H, Lewis MJ, Shah AM. Modulation of left ventricular relaxation in isolated ejecting heart by endogenous nitric oxide. Am J Physiol 1994;267: H1804-13.

17. Paulus WJ, Vantrimpont PJ, Shah AM. Acute effects of nitric oxide on left ventricular relaxation and diastolic distensibility in humans: assessment by bicoronary sodium nitroprusside infusion. Circulation 1994;89:2070-8.

18. Clarkson PB, Lim PO, MacDonald TM. Influence of basal nitric oxide secretion on cardiac function in man. Br $\mathrm{J}$ Clin Pharmacol 1995;40:299-305.

19. Mohan P, Sys SU, Brutsaert DL. Positive inotropic effect of nitric oxide in myocardium. Int J Cardiol 1995;50:233-7.

20. Mohan P, Brutsaert DL, Sys SU. Myocardial performance is modulated by interaction of cardiac endothelium derived nitric oxide and prostaglandins. Cardiovasc Res 1995;29:637-40.

21. Brutsaert DL, Andries LJ. The endocardial endothelium. Am J Physiol 1992;263:H985-1002.

22. Li K, Rouleau JL, Andries LJ, Brutsaert DL. Effect of dysfunctional vascular endothelium on myocardial performance in isolated papillary muscles. Circ Res 1993; 72:768-77.

23. Sunnergren KP, Rovetto MJ. Myocyte and endothelial injury with ischemia reperfusion in isolated rat hearts. Am J Physiol 1987;252:H1211-7.

24. Forman MB, Puett DW, Virmani R. Endothelial and myocardial injury during ischemia and reperfusion: pathogenesis and therapeutic implications. J Am Coll Cardiol 1989;13: 450-9.

25. Hiramatsu T, Forbess JM, Miura T, Mayer JE Jr. Effects of $\mathrm{L}$-arginine and $\mathrm{L}$-nitro-arginine methyl ester on recovery of neonatal lamb hearts after cold ischemia: evidence for an important role of endothelial production of nitric oxide. $\mathbf{J}$ Thorac Cardiovasc Surg 1995;109:81-6.

26. Engelman DT, Watanabe $M$, Maulik $N$, et al. L-Arginine reduces endothelial inflammation and myocardial stunning during ischemia/reperfusion. Ann Thorac Surg 1995;60:127581.

27. Hammon JW Jr, Vinten-Johansen J. Augmentation of microvascular nitric oxide improves myocardial performance following global ischemia. J Card Surg 1995;10:423-7.

28. Fischell TA, Nellessen U, Johnson DE, Ginsburg R. Endothelium-dependent arterial vasoconstriction after balloon angioplasty. Circulation 1989;79:899-910.

29. Wallace A. Do deficiencies of endothelial derived relaxing factor contribute to myocardial stunning? J Card Surg 1993; 8(Suppl):325-8. 